Editorial

\title{
Recent advances and applications in accessibility modelling
}

Accessibility is a concept that has become central to physical planning and spatial modelling for more than fifty years. As measure of the relative nearness or proximity of one place and persons to all other places or persons, conceptually linked to Newton's law of gravity, its origins can be traced back to the 1920s when it was used in location theory and regional economic planning (Batty, 2009) and retail planning (Stewart, 1948). In his classic paper, Hansen (1959) was the first to define accessibility as a potential of opportunities for interaction and applied the concept to forecast employment developments in Washington D.C. Hansen's gravitybased measure of accessibility was a generalization of the concept of population potential, which was based on the notion of potential in physics systems by Stewart (1948). Since then, accessibility analyses have addressed the issue of spatial interaction. Spatial Interaction Models (SIMs) provide an explicit link between accessibility modelling, and economic, demographic and transport flows. SIMs have a long history and have been used in a wide variety of contexts. Wilson (1970) gave SIMs theoretical strength by deriving them using the entropy maximization approach, and the doublyconstrained form formed the bases for transport flow modelling. The formal equivalence between SIMs and logit models/micro-economic theory was shown by Anas (1983). The accessibility function can be directly derived from SIMs and it therefore contains SIM behavioural cost components (Reggiani, 2014). Moreover, the relevance of topological/connectivity structures in the accessibility analyses has, in some way, been anticipated by Weibull (1980), who considered accessibility as a property of configuration of opportunities for spatial interaction.

Accessibility models have in the past decades been applied in several academic fields such as urban geography, rural geography, health geography, time geography, spatial economics and transport engineering. Many different applications have been developed in these fields and can be categorized in several ways. Here, we use the categorization of accessibility measures from the well-cited review paper from Geurs and Van Wee (2004). They provide an overview of components of accessibility and perspectives on accessibility, which we will use as a categorization of accessibility measures. Geurs and Van Wee distinguish four basic perspectives on accessibility: (i) infrastructure-based measures, analyzing the performance or service level of transport infrastructure, (ii) location-based measures, analyzing accessibility of spatially distributed activities, typically on an aggregate level, (iii) person-based measures, founded in the space-time geography, analyzing accessibility at the level of the individual level, and (iv) utility-based measures, analyzing the welfare benefits that people derive from levels of access to the spatially distributed activities.

These perspectives focus on one or several of the four components of accessibility distinguished by Geurs and Van Wee: (i) the land-use component reflecting the amount, quality and spatial distribution of opportunities, (ii) the transportation component describing the disutility of travel in terms of time, cost and effort, (iii) the temporal component reflecting the temporal constraints and variability, and (iv) the individual component reflecting the needs, and abilities of individuals. Here, we describe the directions which academic literature in the recent years took to improve the treatment of the four components in accessibility modelling.

Several research directions target the improvement of the land use component of accessibility in accessibility modelling. This follows the continuing trend from the past decade or more to develop more complex and disaggregated accessibility measures. These trends partly result from improvements in techniques to construct location-based accessibility indicators. These techniques have evolved from simple calculations to complex and detailed methods that use algorithms within a Geographic Information Systems (GIS) platform to estimate for example block-level accessibility (e.g. Chen et al., 2011). A new generation of accessibility models will also benefit from advances in geospatial technology. The new geographic information science for transport analysis (also known as GIS-T) includes powerful instruments for modelling and visualizing accessibility (Thill, 2009). Furthermore, an upcoming research stream focuses on web-based mapping and applications that use internet technologies to retrieve detailed information about local amenities. Páez, Moniruzzaman, Bourbonnais, and Morency (2013), for example, developed a web-based accessibility instrument employing Google Maps API to retrieve information about local amenities (e.g. groceries, restaurants, fitness, banks, etc.) and estimate accessibility by car, walking and cycling. Other academics developed accessibility models including location-based competition, which occurs when there is a mismatch in the spatial distribution of population (or population segments) and opportunities with capacity constraints. Academic research focuses on competition for jobs (e.g., Cheng \& Bertolini, 2013; Geurs \& Ritsema van Eck, 2003) and health care facilities (e.g., Dewulf, Neutens, De Weerdt, \& Van De Weghe, 2013; Wan, Zou, \& Sternberg, 2012). In this special issue, Wang, Monzón, \& Di Ciommo introduced an adapted accessibility indicator taking into account jobs competition for Madrid, Spain. Despite the higher level of detail in the treatment of the land use component, there remains a lack of attention for the dynamic relationship between land-use and accessibility in accessibility modelling studies. This is despite the fact that the two-way interaction between transport and land-use has been one of the central research topics of transport studies (e.g., Banister \& Berechman, 2001) and academic research on land-use/transport-interaction (LUTI) modelling is growing (e.g., Chang, 2006; Waddell, 2011). In this Special Issue, Wang et al. and Zondag, de Bok, Geurs, \& Molenwijk show the 
added value of embedding accessibility measures within the framework of a LUTI model. Zondag et al., for example, show that modest changes in location choices of residents and firms can have significant effects on the accessibility benefits of public transport investments.

A second set of research directions target the transport component of accessibility. The transportation component of accessibility measures is often assumed based on conventions, and reasonable expectations on the part of the analyst (see Páez, Scott, \& Morency, 2012, for a review). However, there is growing attention for actual measures of travel behaviour or travel costs as perceived by the traveler (subjective accessibility). Krizek, Horning, and ElGeneidy (2012), for example, show that individuals' perception of walking accessibility to retail is fraught with error. Curl, Nelson, \& Anable (this issue) compare objective to subjective accessibility measures through logistic regression models in England, UK and finds significant discordance between the two. The differences vary spatially (between urban and rural settings), destination (e.g. familiar and unfamiliar destinations) and socially (e.g., age). Moreover, a growing number of accessibility studies is examining the vulnerability and resilience of transport systems to sudden disruptions, contrasting the mainstream of research examining accessibility under 'normal' circumstances. In this issue, Jenelius and Mattsson adopt vulnerability measures to the road system of Sweden as proxy for accessibility decay, and Östh, Reggiani, \& Galiazzo analyze the interplay between accessibility and economic resilience at the level of municipalities of Sweden. Osth et al. show that economic resilience varies strongly between urban and rural areas. Rural municipalities in Sweden with estimates of poor resilience and poor accessibility in general also experience population loss. However, the relationship between resilience and accessibility seems not strictly linear. In this issue, Caschili, De Montis, \& Trogu also show the interplay between accessibility and rurality at the level of municipality in Sardinia, Italy, using spatial autocorrelation analysis. They find that there is not always a spatial correlation between accessibility and rurality of an area. In an era where cities triumph (Glaeser, 2012) over rural areas with declining and ageing populations, the complexity of urban-rural interactions is a research area which deserves more attention, also in the light if accessibility issues (Taylor, \& Susilawati, 2012).

A third, and growing field of accessibility modelling is related to temporal dynamics in accessibility. So far, mainstream accessibility models can all be considered static measures of access, since the score for a particular location does not vary temporally, which as a result may not suitably represent the actual levels of access for different population groups and activity purposes. However, nowadays, time-of-day variations in road network accessibility can be examined using realtime driving speeds on road networks based on GPS measurements from mobile phones and navigation systems such as TomTom or NavTeq. Recent advances in geospatial technology, open source web-based mapping (e.g., OpenStreetMap) and public availability of Transit Feed Specification (GTFS) data from transit authorities gives room for a growing field of research on time-of-day variations in public transit accessibility (e.g., Lei, Chen, \& Goulias, 2012; Owen, \& Levinson, 2014).

Fourthly, and finally, person-based accessibility measures, measuring accessibility at the individual level as opposed to a zonal levels, also remains to attract academic research, partly in response to recognizing that location-based measures are less suited for understanding the complexities of and individual difference in human spatial behaviour (Kwan, \& Weber, 2003). For example, recent studies examined the spatial variation in opportunities for social interaction (e.g., Neutens, Farber, Delafontaine, \& Boussauw, 2013; Farber and Li, 2013). A related direction of accessibility research focuses on measuring the social dimension of transport using accessibility concepts, using location-based or person-based accessibility concepts to social exclusion, social equity, and/or social justice (e.g., Achuthan, Titheridge, \& Mackett, 2010; Bocarejo S and Oviedo H, 2012).

It seems with advances in geospatial technology, internet technology, and abundance of detailed spatial data and real-time transport data sets, the field of accessibility modelling is thriving. In this era of data abundance, reflections on the role of accessibility modelling are more than ever important in the search for sound and interdisciplinary accessibility theories and tools. This is the rationale which characterizes the articles included in this Special Issue. Some of the contributions in this special issue have been inspired by concepts and ideas discussed in the papers presented in a ERSA-NECTAR ${ }^{1}$ Special Session on Accessibility and Spatial Patterns organized by Andrea De Montis and Aura Reggiani in the context of the ERSA 50th Conference held in Jønkøping (Sweden) on 19-23 August 2010.

In Table 1, the focus of the six articles collected in this Special Issue is further explained with a classification using the following main features:

1. The main component of accessibility on which analysis focuses;

2. Transportation system indicates to which transportation context the authors are referring;

3. Region, country elucidates the national context under analysis;

4. Socio-economic variable refers to the categories of people that are analyzed in their mobility/accessibility choices;

5. Spatial unit explains the level of spatial organization of the data;

6. Time period reports the time span when the data were collected;

7. Methodology indicates the analytical tool(s) adopted for constructing the accessibility measures;

8. Accessibility measurements/proxy reports on the measurements used to calculate the level of accessibility.

The papers included in this special issue are interrelated and show a number of common concepts. Some papers approach accessibility by defining for the first time or post processing measures of complex socio-economic phenomena assessed through multi-component indicators. Curl et al. consider composite measures provided by the two datasets Core Accessibility Indicators (CAI) and National Travel Survey (NTS), while Caschili et al. explore the interplay between accessibility and Composite Indicator of Rurality (CIR), and Östh et al. study the relation between accessibility and Resilience Capacity Index (RCI). Another leitmotif, as noted earlier, is the adoption of instruments falling in the cluster of Land-Use and Transport Interaction (LUTI) models. Zondag et al. describe the characteristics of TIGRIS XL, a national modelling framework able to perform, inter alia, discrete choice modelling in the context of a recursive quasi dynamic LUTI model. Wang et al. work out a LUTI model, i.e. the Metropolitan Activity Relocation Simulator (MARS), while introducing an adaptive accessibility indicator. Accessibility is defined in some papers by invoking the efficiency of the system in a dynamic context. So Jenelius and Mattsson focus on vulnerability, i.e. the social risk of transport system disruption and degradation, while Östh et al. commit themselves to resilience, i.e. the capacity to resist to or to recover from shocks. Some authors adopt the definition of accessibility as potential of opportunity for interaction. In this context, Caschili et al. describe commuter movements between municipalities in a European region, Wang et al. model the displacement of individuals in a European city, and Östh et al. do so at the level of municipalities in a European state. In two papers, the authors adopt Spatial Interaction Modelling (SIM) techniques to calibrate the description of the movement

\footnotetext{
${ }^{1}$ ERSA (European Regional Science Association): http://www.ersa.org/; NECTAR (Network on European Communications and Transport Activity Research): http://
} www.nectar-eu.org. 
to the relational behaviour of the agents belonging to the entire spatial system. In this direction, Caschili et al. and Östh et al. deploy a doubly-constrained SIM by managing the calibration of two balancing factors and time-distance cost sensitivity parameters, which vary depending on the location.

From the overview of literature and the papers in this special issue it will firstly be clear that considerable progress has been made in accessibility modelling in recent years. However, at the same time, the papers in this issue show a clear need for additional research on several topics, such as the inclusion of user perceptions of transport impedance factors, the dynamic relationship between land-use and accessibility in accessibility modelling studies, the relationships between accessibility, vulnerability, resilience and transport in spatial networks, and, consequently, the relationship between accessibility and network connectivity at different scale levels (urban, regional, national, etc.). Secondly, it is clear that advances in accessibility models have taken many different directions. Accessibility is a multifaceted concept which make the development of different approaches and models appealing for researchers but at the same time a confusing amount of definitions, approaches and modelling outcomes are generated with increasingly higher spatial resolutions. A first direction for future accessibility research would be to develop more unified and comprehensive conceptions of accessibility and test them in practice. These would need to bring together different dimensions of accessibility (e.g., economic, social, cognitive and psychological) and incorporate relevant transport and communication modes, user groups and travel generating opportunities (Geurs et al., 2012). A second, and more practical, research direction would be to focus on comparative accessibility studies to sort out which approaches and model specifications are appropriate for which study purpose and spatial context. From existing comparative studies it is well known that different accessibility approaches and specifications (e.g., using different distance decay functions, or different connectivity structures) can lead to very different conclusions for the same study area (e.g., Kwan, 1998; Linneker \& Spence, 1992; Neutens, Schwanen, Witlox, \& de Maeyer, 2010; Thill \& Kim, 2005).

\section{References}

Achuthan, K., Titheridge, H., \& Mackett, R. L. (2010). Mapping accessibility differences for the whole journey and for socially excluded groups of people. Journal of Maps, 6, 220-229.

Anas, A. (1983). Discrete choice theory, information theory and the multinomial logit and gravity models. Transportation Research Part B: Methodological, 17. $13-23$.

Banister, D., \& Berechman, Y. (2001). Transport investment and the promotion of economic growth. Journal of Transport Geography, 9, 209-218.

Batty, M. (2009). Accessibility: In search of a unified theory. Environment and Planning B: Planning and Design, 36, 191-194.

Bocarejo S, J. P., \& Oviedo H, D. R. (2012). Transport accessibility and social inequities: A tool for identification of mobility needs and evaluation of transport investments. Journal of Transport Geography, 24, 142-154.

Caschili, S., De Montis, A., Trogu, D. (this special issue) Accessibility and rurality indicators for regional development. Computers, Environment and Urban Systems.

Chang, J. S. (2006). Models of the relationship between transport and land-use: A review. Transport Reviews, 26(3), 325-350.

Chen, Y., Ravulaparthy, S., Deutsch, K., Dalal, P., Yoon, S. Y., Lei, T., et al (2011). Development of indicators of opportunity-based accessibility. Transportation Research Record: Journal of the Transportation Research Board, 2255, 58-68.

Cheng, J., \& Bertolini, L. (2013). Measuring urban job accessibility with distance decay, competition and diversity. Journal of Transport Geography, 30, 100-109.

Curl, A., Nelson, J., Anable, J. (this special issue). Same question, different answer: A comparison of gis-based journey time accessibility with self-reported measures from the English National Travel Survey. Computers, Environment and Urban Systems.

Dewulf, B., Neutens, T., De Weerdt, Y., Van De Weghe, N. (2013). Accessibility to primary health care in Belgium: An evaluation of policies awarding financial assistance in shortage areas. BMC Family Practice, 14, 122. <http:/| www.biomedcentral.com/1471-2296/14/122>

Farber, S., \& Li, X. (2013). Urban sprawl and social interaction potential: An empirical analysis of large metropolitan regions in the United States. Journal of Transport Geography, 31, 267-277. 
Geurs, K. T., \& Ritsema van Eck, J. R. (2003). Accessibility evaluation of land-use scenarios: The impact of job competition, land-use and infrastructure developments for the Netherlands. Environment and Planning B, 30(1), 69-87.

Geurs, K. T., \& van Wee, B. (2004). Accessibility evaluation of land-use and transport strategies: Review and research directions. Journal of Transport Geography, 12, 127-140.

Geurs, K. T., Krizek, K., \& Reggiani, A. (Eds.). (2012). Accessibility analysis and transport planning: Challenges for Europe and North America. Northampton, USA: Edward Elgar.

Glaeser, E. (2012). Viewpoint: Triumph of the city. Journal of Transport and Land Use, $5(2), 1-4$.

Hansen, W. G. (1959). How accessibility shapes land use. Journal of American Institute of Planners, 25(1), 73-76.

Jenelius, E., Mattsson, L.-G. (this special issue). Road network vulnerability analysis: Conceptualization, implementation and application. Computers, Environment and Urban Systems.

Krizek, K. J., Horning, J., \& El-Geneidy, A. (2012). Perceptions of accessibility to neighbourhood retail and other public services. In K. T. Geurs, K. J. Krizek, \& A Reggiani (Eds.), Accessibility analysis and transport planning: Challenges for Europe and North America (pp. 96-117). Cheltenham: Edwar Elgar Publishing.

Kwan, M.-P. (1998). Space-time and integral measures of individual accessibility: A comparative analysis using a point-based framework. Geographical Analysis, 30(3), 191-216.

Kwan, M.-P., \& Weber, J. (2003). Individual accessibility revisited: Implications for geographical analysis in the twenty-first century. Geographical Analysis, 35(4), 341-353.

Lei, T., Chen, Y., \& Goulias, K. (2012). Opportunity-based dynamic transit accessibility in Southern California. Transportation Research Record: Journal of the Transportation Research Board, 2276(3), 26-37.

Linneker, B. J., \& Spence, N. A. (1992). Accessibility measures compared in an analysis of the impact of the M25 London Orbital Motorway on Britain. Environment and Planning A, 24, 1137-1154.

Neutens, T., Farber, S., Delafontaine, M., \& Boussauw, K. (2013). Spatial variation in the potential for social interaction: A case study in Flanders (Belgium). Computers, Environment and Urban Systems, 41, 318-331.

Neutens, T., Schwanen, T., Witlox, F., \& de Maeyer, P. (2010). Equity of urban service delivery: A comparison of different accessibility measures. Environment and Planning A, 42(7), 1613-1635.

Östh, J., Reggiani, A., Galiazzo, G. (this special issue). Regional economic resilience and accessibility: A joint perspective. Computers, Environment and Urban Systems.

Owen, A., Levinson, D. M. (2014). Modeling the commute mode share of transit using continuous accessibility to jobs, 93rd Annual meeting of the transportation research board, Washington, D.C.

Páez, A., Moniruzzaman, M. D., Bourbonnais, P., \& Morency, C. (2013). Developing a web-based accessibility calculator prototype for the Greater Montreal Area. Transportation Research Part A: Policy and Practice, 58, 103-115.
Páez, A., Scott, D. M., \& Morency, C. (2012). Measuring accessibility: Positive and normative implementations of various accessibility indicators. Journal of Transport Geography, 25, 141-153.

Reggiani, A. (2014). Complexity and spatial networks. In M. Fischer \& P. Nijkamp (Eds.), Handbook of regional science (pp. 811-832). Berlin, Heidelberg and New York: Springer.

Stewart, J. Q. (1948). Demographic gravitation: Evidence and application. Sociometry, 11, 31-58.

Taylor, M. A. P., \& Susilawati (2012). Remoteness and accessibility in the vulnerability analysis of regional road networks. Transportation Research Part A: Policy and Practice, 46(5), 761-771.

Thill, J.-C., \& Kim, M. (2005). Trip making, induced travel demand, and accessibility. Journal of Geographical Systems, 7(2), 229-248.

Thill, J.-C. (2009). Transportation applications of geographic information systems. In M. Madden (Ed.), Manual of geographic information systems (pp. 1035-1049). Washington, DC: ASPRS.

Waddell, P. (2011). Integrated land use and transportation planning and modelling: Addressing challenges in research and practice. Transport Reviews, 31, 209-229.

Wan, N. Zou, B., \& Sternberg, T. (2012). A three-step floating catchment area method for analyzing spatial access to health services. International Journal of Geographical Information Science, 26(6), 1073-1089.

Wang, Y., Monzón A., Di Ciommo F. (this special issue). Assessing the impact of adapted potential accessibility on optimal transport policy using a land use and transport interaction model for Madrid. Computers, Environment and Urban Systems.

Weibull, J. W. (1980). On the numerical measurement of accessibility. Environment and Planning A, 12, 53-67.

Wilson, A. G. (1970). Entropy in urban and regional modelling. London: PION.

Zondag, B. de, de Bok, M., Geurs, K., Molenwijk, E. (this special issue). Accessibility modeling and evaluation: The TIGRIS XL land-use and transport interaction model for the Netherlands. Computers, Environment and Urban Systems.

Karst T. Geurs

Centre for Transport Studies, University of Twente, The Netherlands E-mail address: k.t.geurs@utwente.nl

Andrea De Montis

Dipartimento di Agraria, University of Sassari, Italy E-mail address: andreadm@uniss.it

Aura Reggiani

Department of Economics, University of Bologna, Italy E-mail address: aura.reggiani@unibo.it

Available online 3 October 2014 